\title{
TOMOGRAFIA COMPUTADORIZADA: VANTAGENS SOBRE A RADIOGRAFIA PANORÂMICA NA ANALISE DE TERCEIROS MOLARES INFERIORES INCLUSOS.
}

Carolina LAZAROTTO, Grasielle KARPSTEIN, Wilson Kenji SHIROMA

A cirurgia dos terceiros molares inferiores retidos pode levar a alterações sensoriais importantes, devido a trauma no nervo alveolar inferior, o qual no seu trajeto apresenta relação intra-óssea importante com as raízes dos molares. A relação entre os ápices do terceiro molar e o canal mandibular deve ser previamente identificada à intervenção cirúrgica. O presente trabalho tem por objetivo a comparação das imagens, da relação dos terceiros molares inferiores retidos com o canal mandibular, fornecidas por radiografias panorâmicas (RP) e por tomografias computadorizadas (TC). Por meio de comparação de radiografias panorâmicas e suas respectivas TC, levando em consideração a relação de proximidade dos ápices dentários com o canal mandibular, foram obtidos os seguintes resultados: das RP avaliadas, todas apresentaram imagem de sobreposição do canal mandibular, e uma delas, também sugeriu trajeto interradicular do mesmo. Na TC comprovou-se tridimensionalmente relação de proximidade dos mesmos e em um caso, descartou-se a possibilidade de um trajeto interradicular do canal mandibular. Portanto, pelo material analisado, sugere-se que a TC mostra-se superior no diagnóstico e planejamento cirúrgico de terceiros molares inclusos. 